\title{
Intermédialités
}

Histoire et théorie des arts, des lettres et des techniques

Intermediality

History and Theory of the Arts, Literature and Technologies

\section{In transit}

\section{Maria Papadimitriou}

Numéro 10, automne 2007

Disparaître

Disappearing

URI : https://id.erudit.org/iderudit/1005561ar

DOI : https://doi.org/10.7202/1005561ar

Aller au sommaire du numéro

Éditeur(s)

Centre de recherche sur l'intermédialité

ISSN

1705-8546 (imprimé)

1920-3136 (numérique)

Découvrir la revue

Citer ce document

Papadimitriou, M. (2007). In transit. Intermédialités / Intermediality, (10),

190-205. https://doi.org/10.7202/1005561ar d'utilisation que vous pouvez consulter en ligne.

https://apropos.erudit.org/fr/usagers/politique-dutilisation/ 


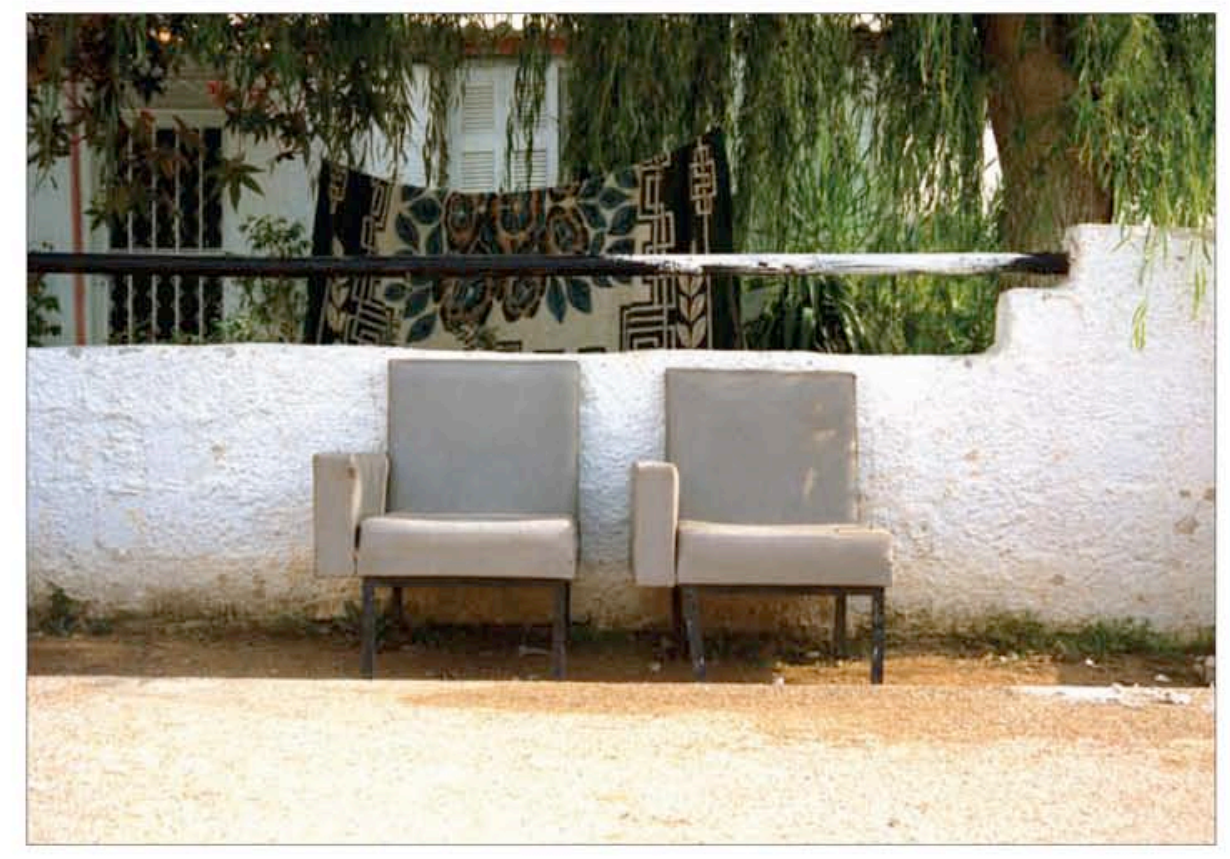

T.A.M.A. (Temporary Autonomous Museum for All): Sans titre, 1998. Tirage Lambda, $1,26 \mathrm{~m} \times 1,8 \mathrm{om}$, tiré à 5 exemplaires. Collection privée.

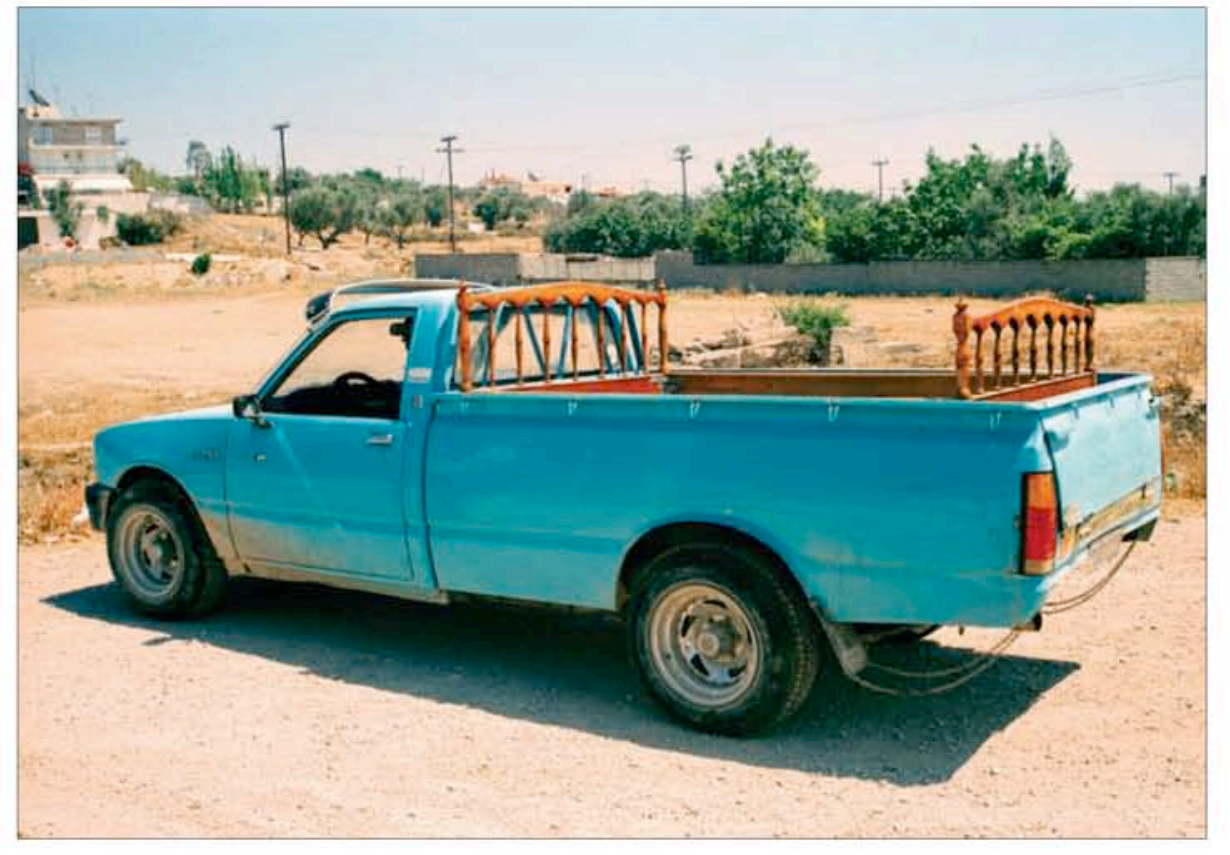

T.A.M.A. (Temporary Autonomous Museum for All): Luv Car

(TransBonanza Platform for Public Events), 2003

Sculpture publique, dimensions variables. Avec l'aimable permission de l'artistc. 


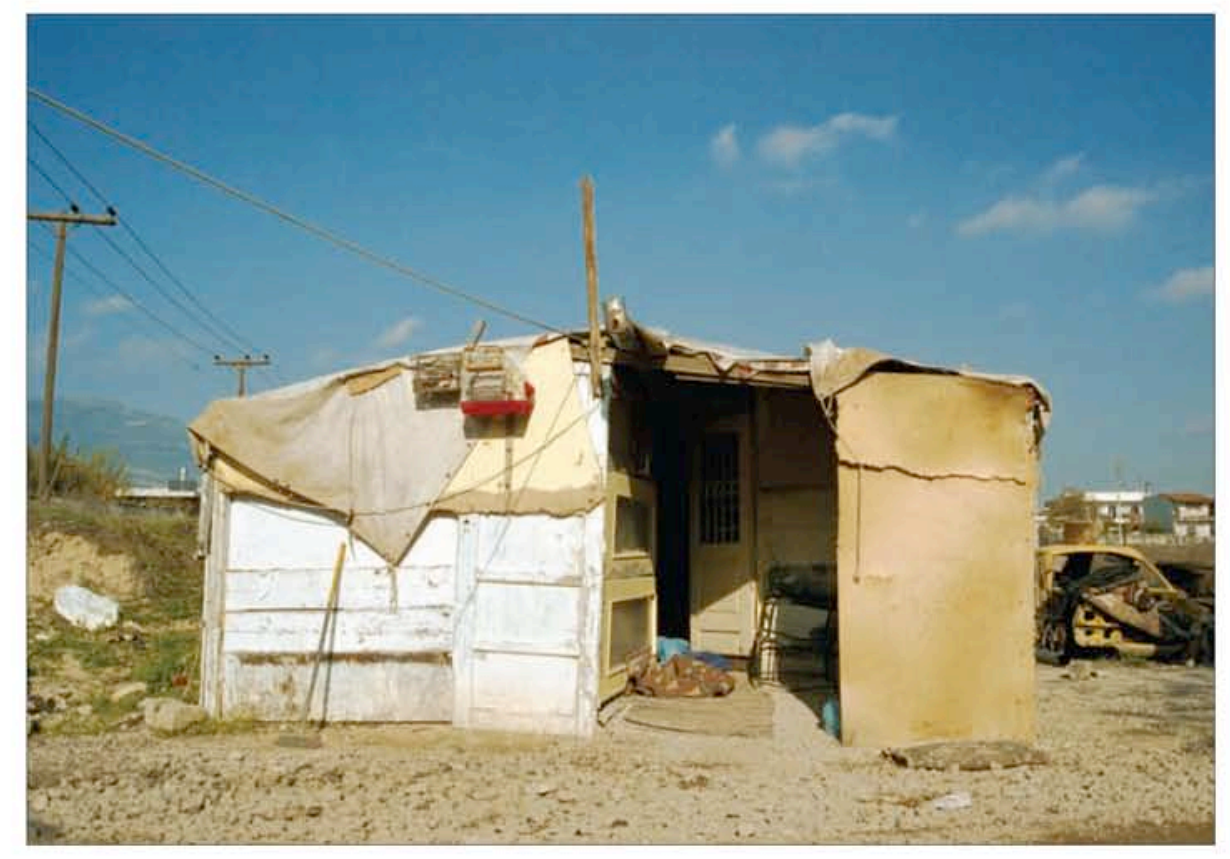

T.A.M.A. (Temporary Autonomous Museum for All): Sans titre, 1999 Tirage Lambda, 1,26m × 1,8om, tiré à 5 exemplaires. Collection privée.

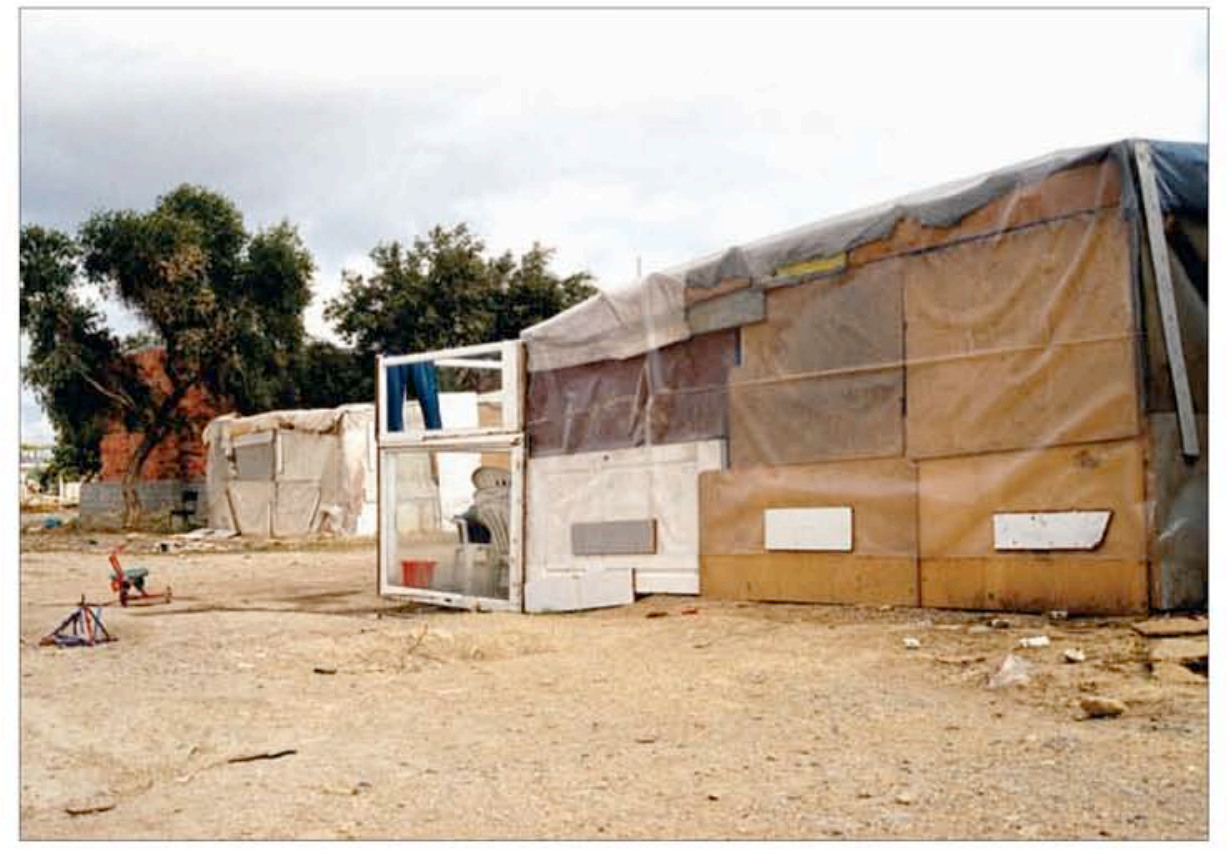

T.A.M.A. (Temporary Autonomous Museum for All): Sans titre, 1999. Tirage Lambda, $1,26 \mathrm{~m} \times 1,8 \mathrm{om}$, tiré à 5 exemplaires. Collection privée. 


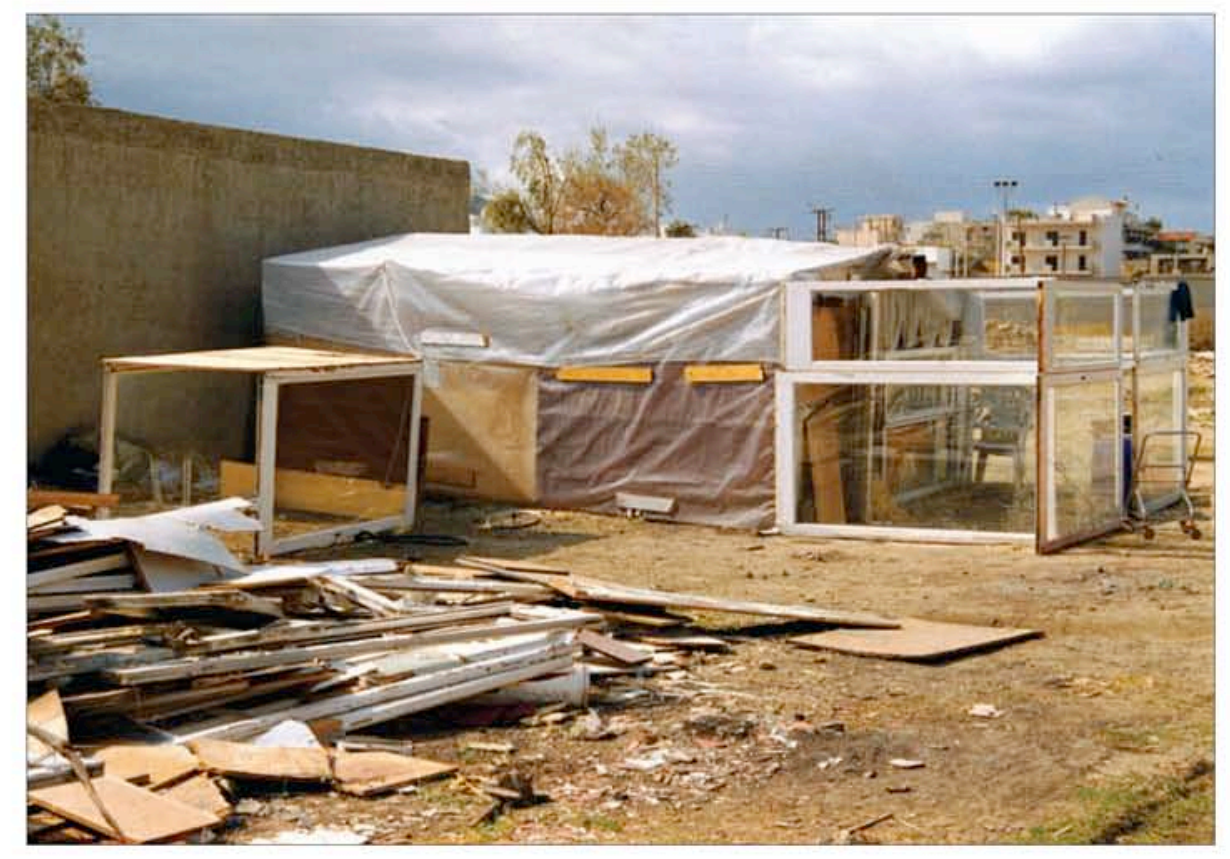

T.A.M.A. (Temporary Autonomous Museum for All): Sans titre, 2000. Tirage Lambda, 1,26m × 1,8om, tiré à 5 exemplaires. Collection privée.

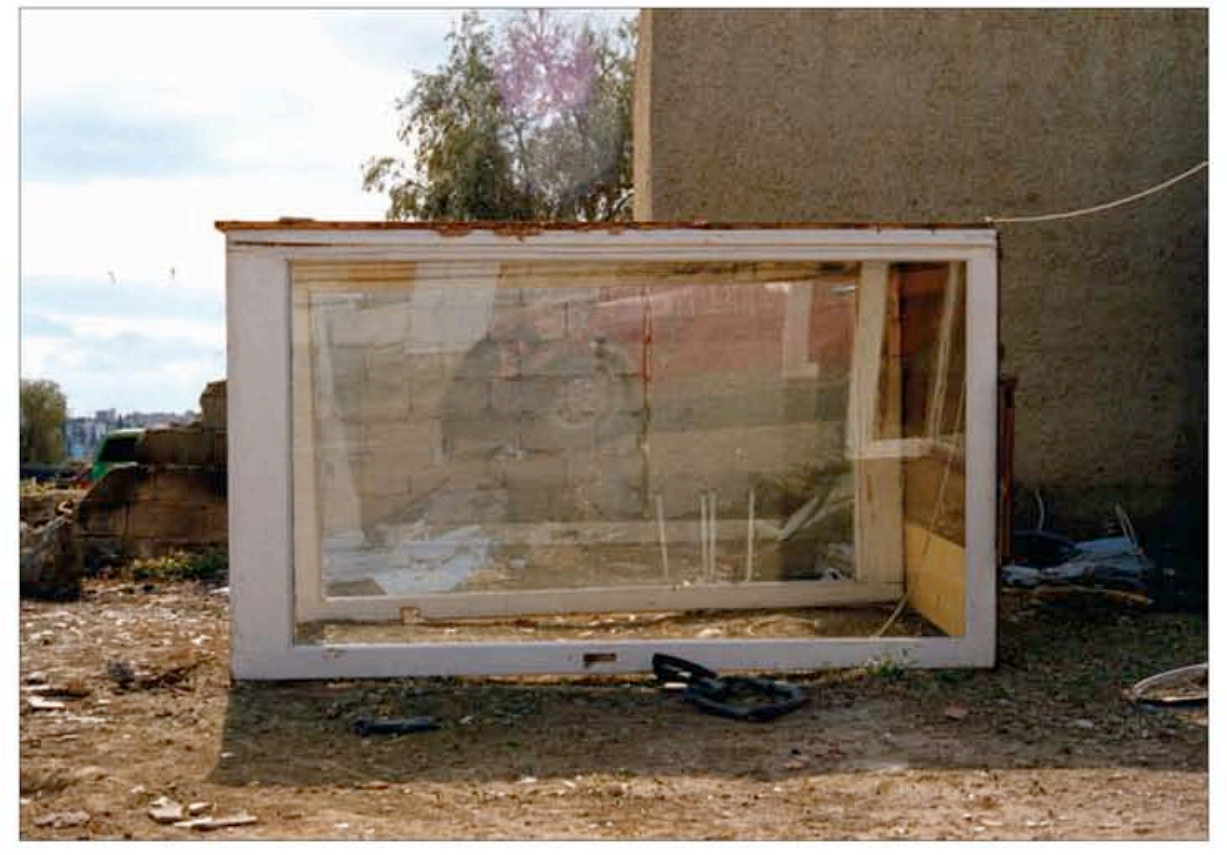

T.A.M.A. (Temporary Autonomous Museum for All): Sans titre, 2000. Tirage Lambda, 1,26m $\times 1,8 \mathrm{om}$, tiré à 5 exemplaires. Collection privée. 


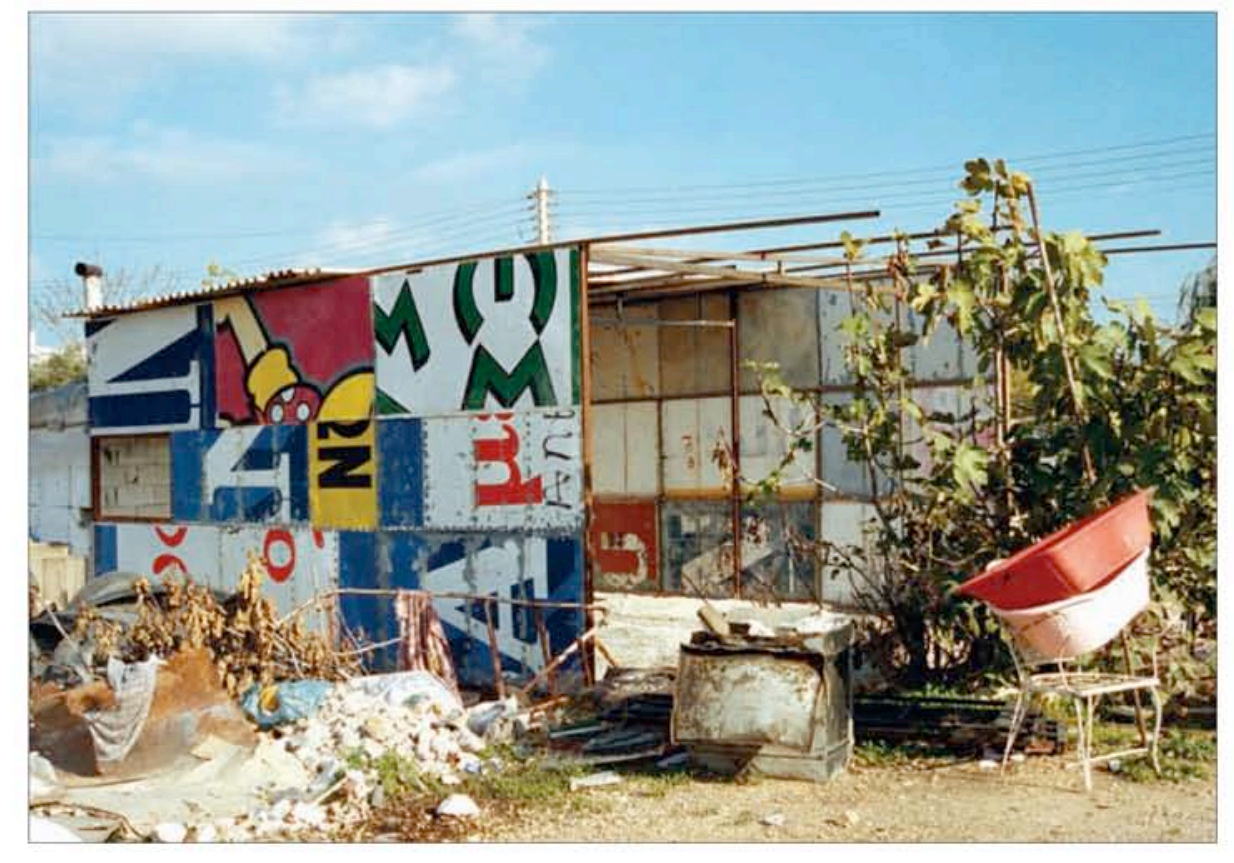

T.A.M.A. (Temporary Autonomous Museum for All): Sans titre, 2000. Tirage Lambda, 1,26m ×1,8om, tiré à 5 exemplaires. Collection privée.

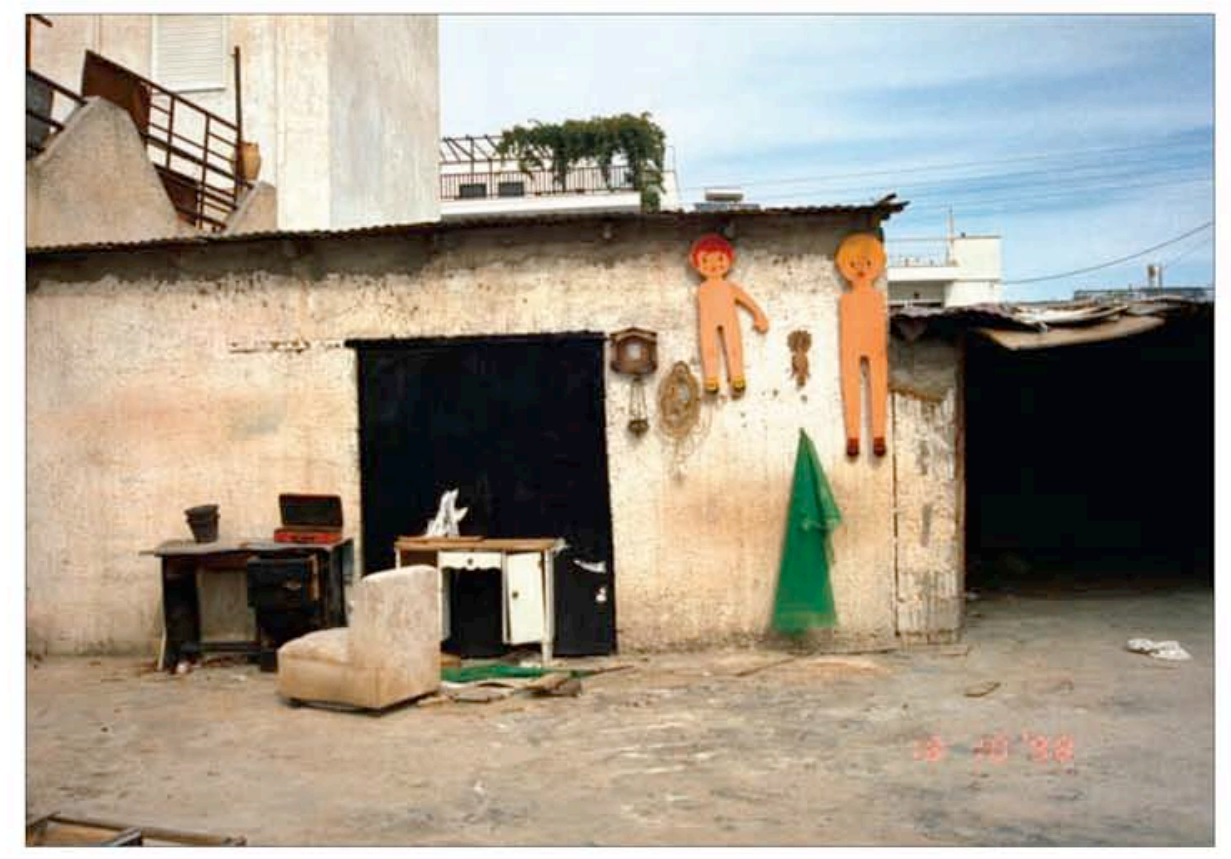

T.A.M.A. (Temporary Autonomous Museum for All): Sans titre, 2000. Tirage Lambda, 1,26m × 1,80m, tiré à 5 exemplaires. Collection privée. 


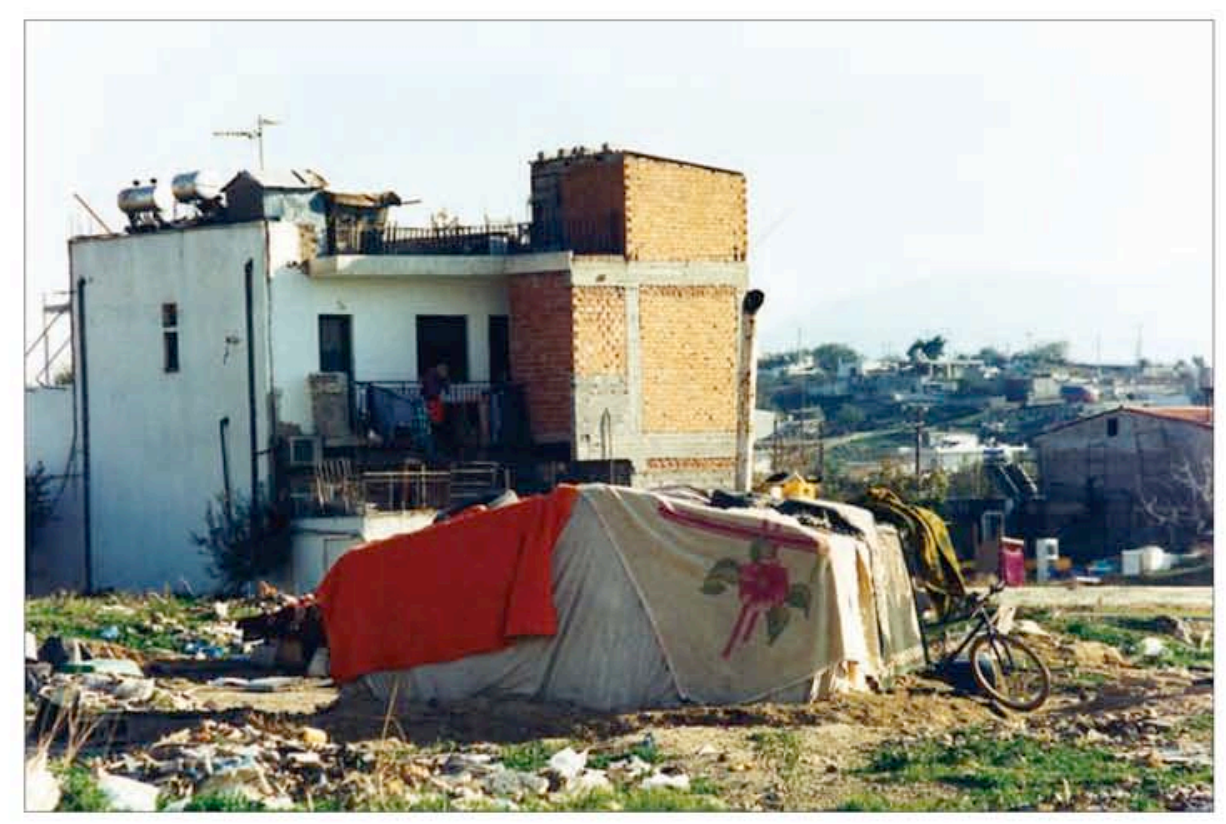

T.A.M.A. (Temporary Autonomous Museum for All): Sans titre, 1998

Tirage Lambda, 1,26m × 1,80m, tiré à 5 exemplaires. Collection privée.

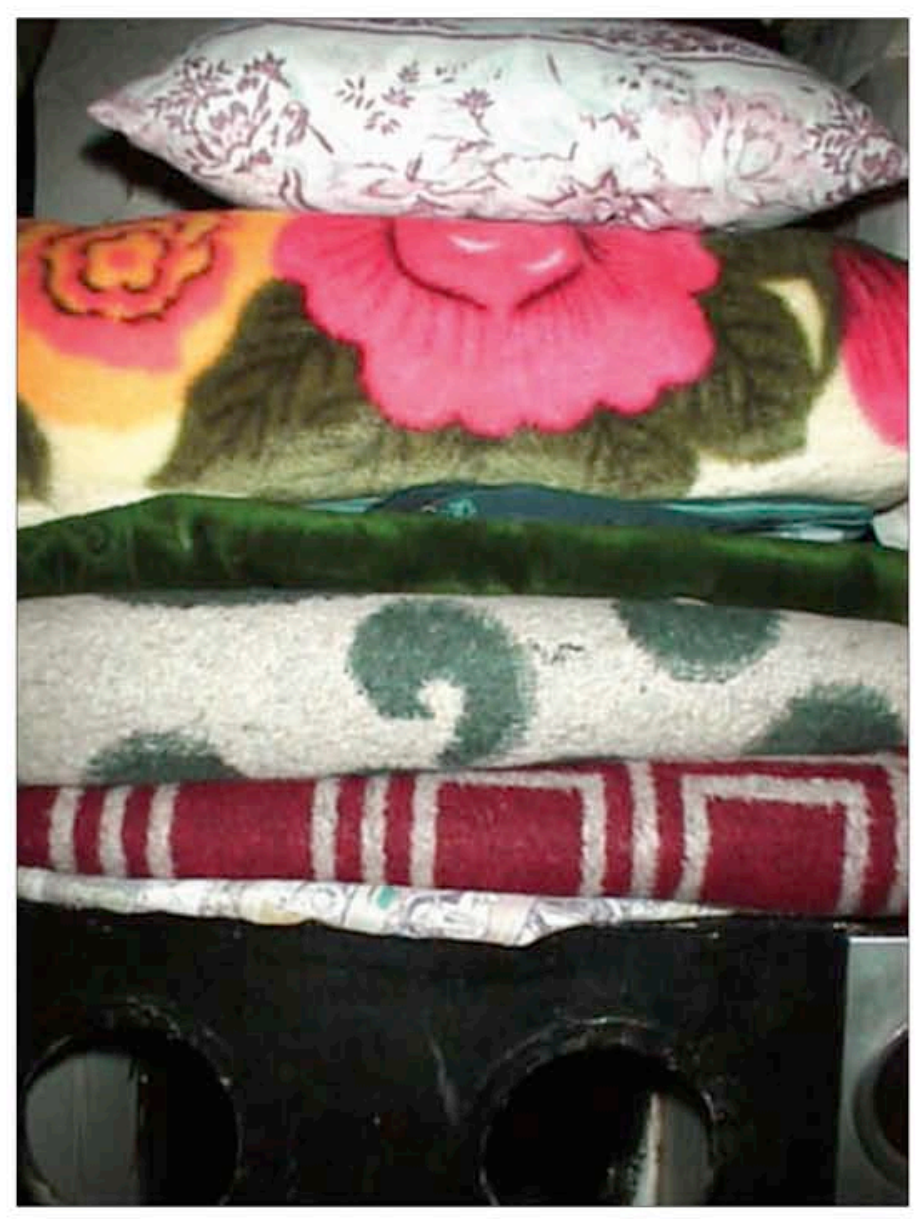

T.A.M.A. (Temporary Autonomous Museum for All): Sans titre, 1999 Tirage Lambda, 1,26m $\times 1,80 \mathrm{~m}$, tiré à 5 exemplaires. Collection privée. 

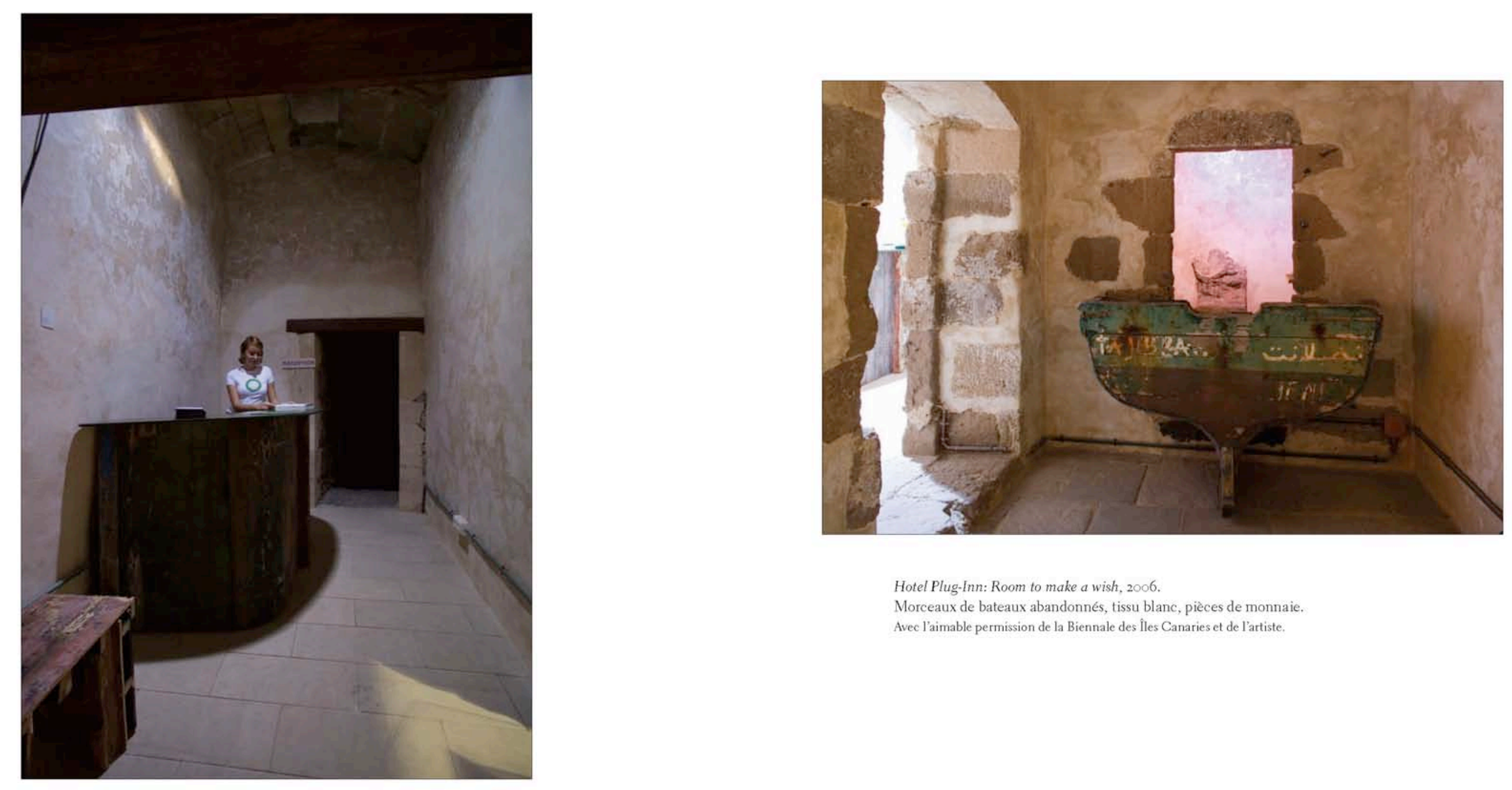

Hotel Plug-Inn: Room to make a wish, 2006.

Morceaux de bateaux abandonnés, tissu blanc, pièces de monnaie. Avec l'aimable permission de la Biennale des Illes Canaries et de l'artiste.

Hotel Plug.Inn: Reception, 2006. Morceaux en bois provenant de bateaux abandonnés par des immigrés illégaux, livres et extraits de journaux,

photographies sur la migration illégale vers les Îles Canaries.

Avec l'aimable permission de la Biennale des Îles Canaries et de l'artiste. 


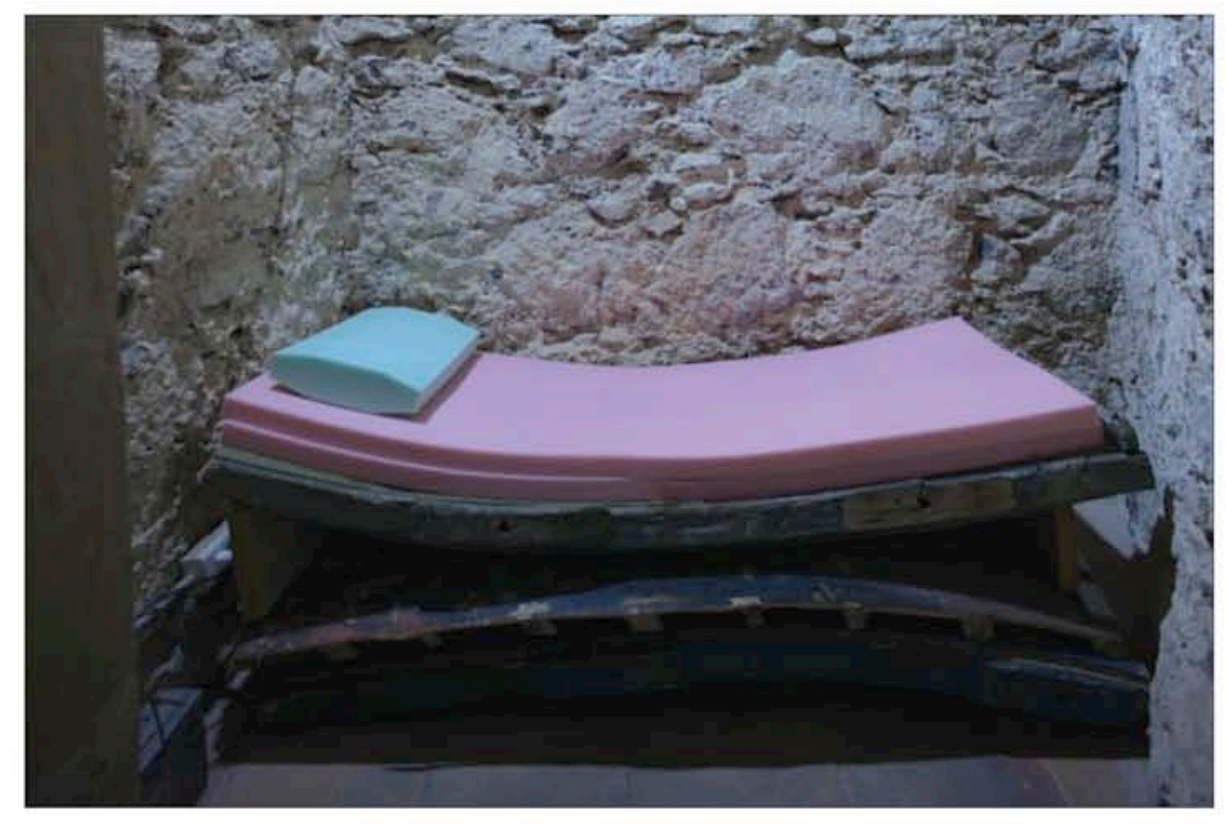

Hotel Plug-Inn: Single room, 2006.

Morceaux de bateaux abandonnés, caoutchouc mousse.

Avec l'aimable permission de la Biennale des Îles Canaries et de l'artiste.

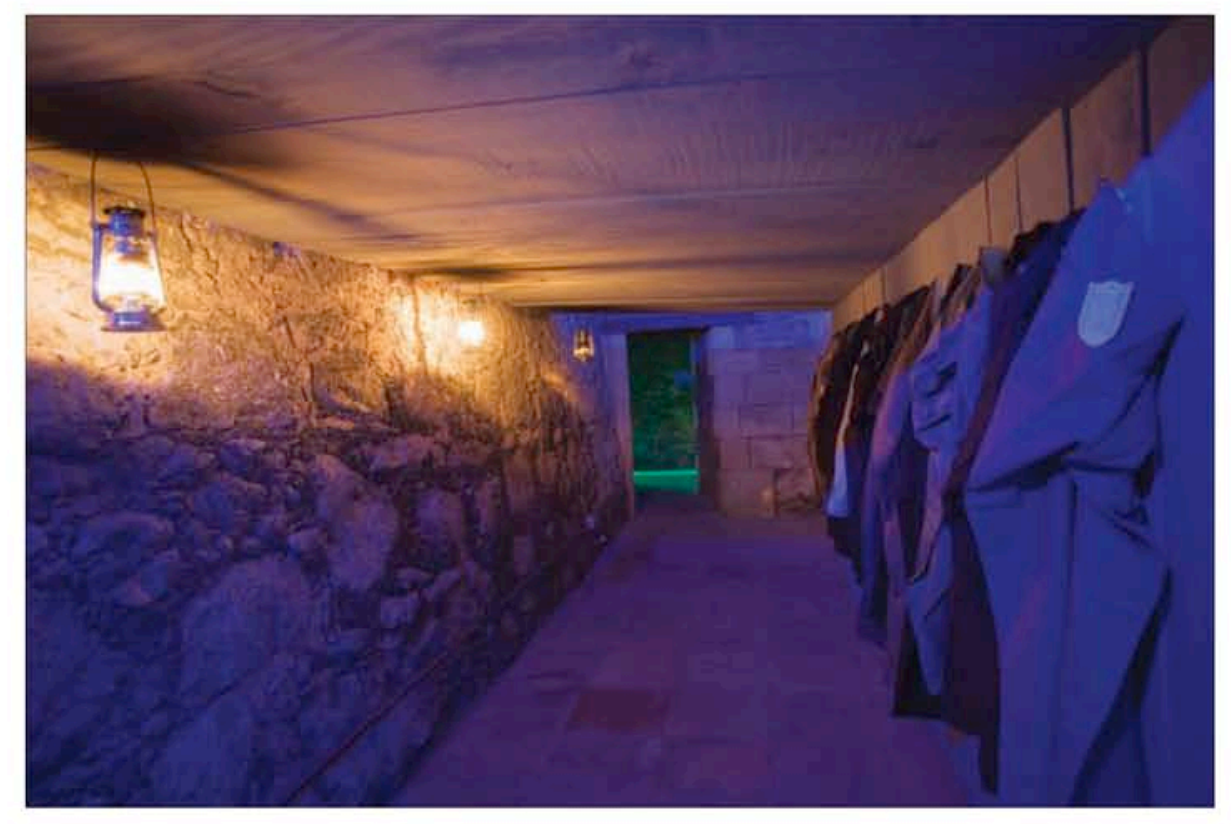

Hotel Plug-Inn: Check-in Room, 2006.

Morceaux de bateaux abandonnés, vêtements, lampes à l'huile. Avec l'aimable permission de la Biennale des Illes Canaries et de l'artistc. 

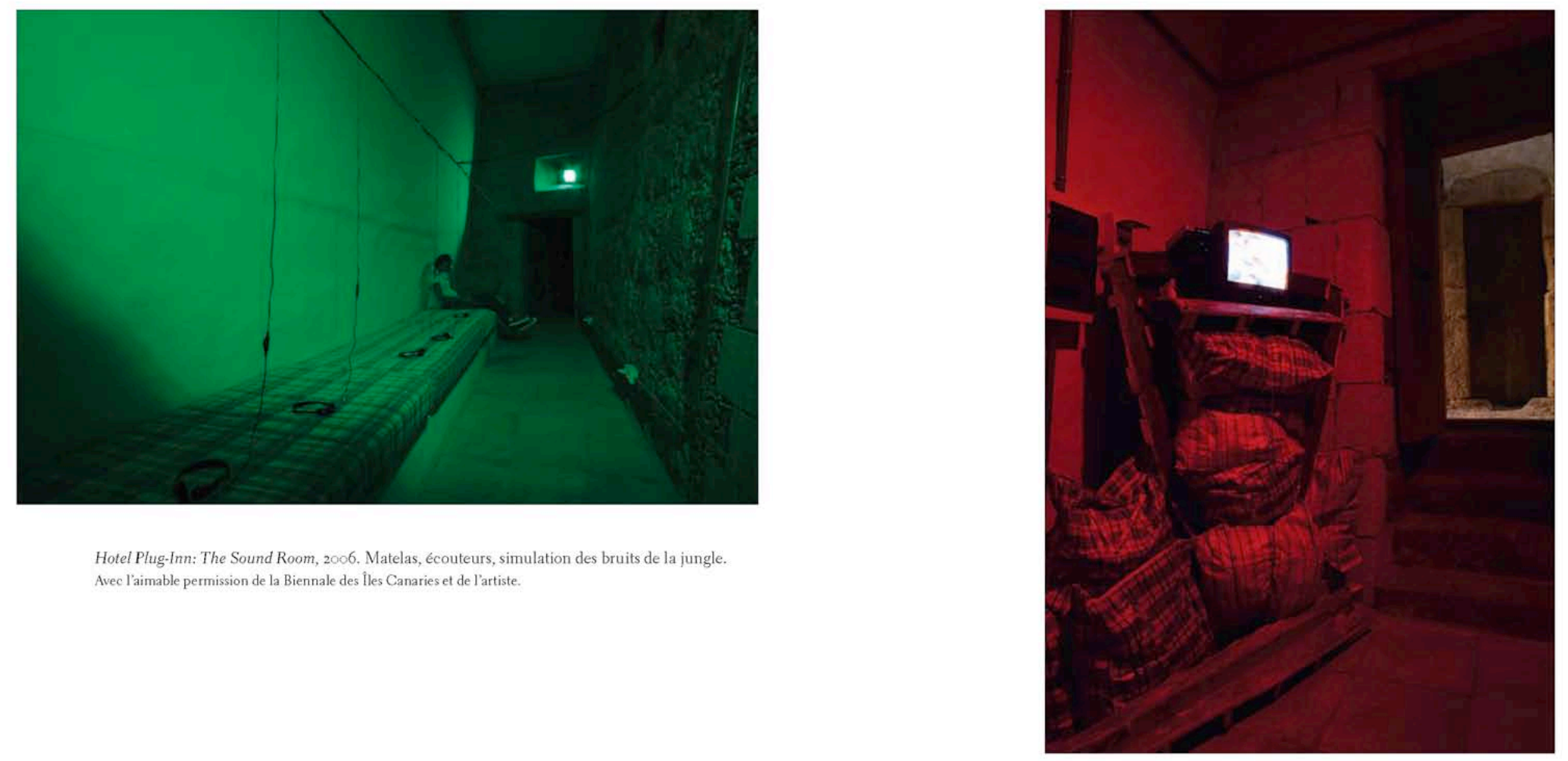

Hotel Plug-Inn: The Sound Room, 2006. Matelas, écouteurs, simulation des bruits de la jungle Avec l'aimable permission de la Biennale des Îles Canaries et de l'artiste.

Hotel Plug-Inn: Exodos, 2006

Morceaux de bateaux abandonnés, sacs en plastique remplis de vêtements, télévision (entrevues avec des immigrés africains illégaux). Avec l'aimable permission de la Biennale des lles Canaries et de l'artiste. 